\title{
Development of a group work assessment pedagogy using constructive alignment theory
}

Suzanne Croy

This is the accepted manuscript $\odot$ 2017, Elsevier Licensed under the Creative Commons AttributionNonCommercial-NoDerivatives 4.0 International: http://creativecommons.org/licenses/by-nc-nd/4.0/

(cc) BY-No-ND

The published article is available from doi:

http://dx.doi.org/10.1016/j.nedt.2017.11.006 
Key words: nurse education; constructive alignment; constructivist: graduate attributes; assessment; group work; reflection.

\section{INTRODUCTION}

Assessment of student learners aims to establish what has been learnt (Biggs 2003; Gibbs 2009; Bloxham 2015). Comprehensive assessment of student nurses' theoretical and practical learning is fundamental to the development of professionals to meet their registration requirements of their regulatory body, in the UK, the Nursing and Midwifery Council (NMC). Constructivism is a learning theory about how people acquire knowledge and learn. Constructivist learning requires the learner being actively involved in making meaning and construction of knowledge during learning as opposed to direct instruction from the teacher.

The aim of constructivist learning theory is to promote comprehensive learning and teaching. Biggs and Tang (2007) describe constructive learning as deep learning, where the student moves beyond learning facts and develops a sense of the larger picture. Biggs and Tang (2007) stated the essential elements of a learning programme include the curriculum teaching methods, assessment procedures, creation of a positive and inclusive learning environment and incorporation of the Higher Education Institute (HEI) graduate attributes, rules and procedures. By aligning these elements, deep learning can occur, but the use of constructivist learning theory is required in order to establish the elements being aligned. The use of aligned teaching design alongside constructivism led to the term of constructive alignment theory (Biggs and Tang 2007).

Fundamental to successful learning is selection of assessment methodology. Bloxham (2015) concluded that assessment methodology should reflect diversity of learning styles, should guide learning, and result in assignment of a quality assured grade which reaches the HEl's academic standards. Assessment methods should be directly related to the module learning outcomes, should encourage development of academic skills, and support development of vocational competencies.

This paper will examine how one HEl combined group work pedagogy, assessment and constructive alignment theory to review the Mental Health Nursing 1 module as part of the BSc (Hons) Nursing programme. The two units of assessment for this module were a group work presentation and completion of an individual reflective online log about learning gained from the module. Initially, there was a lack of consensus amongst teaching staff regarding the most comprehensive and fair way in which to assess group work, and assess whether learning outcomes had been achieved, however the theory of constructive alignment was adopted to adapt the assessment process to value all views and incorporate individual, group and team working skills.

This paper aims to critically discuss constructive alignment theory paying particular attention to the assessment of group work and presents a pedagogical group work assessment underpinned by constructive alignment theory. 


\section{ASSESSMENT OF GROUP WORK}

The assessment of group work has been widely debated in educational literature (Gibbs 2009). Issues include the challenges of delivering fairness, consistency and reliability; in brief, should assessors assign a single summative grade to all group members or should individual achievement within the group context be recognised. Research suggests that student nurses have preferences regarding group work assessment. Smith and Rogers (2014) found that student nurses believed that group work assessment was less representative of individual input than individual assessment; could penalise 'good' students; and should only be used as a form of assessment if it is the best way to assess learning outcomes.

Differing views exist in the literature as to the most effective way in which to grade assessment of group work" and group work assessments. Allocation of a single group mark has been associated with freeloading; loss of potential individual learning benefits; and unfairness. In a study by Smith and Rogers (2014) $74 \%$ of students agreed that assessing individual members' contributions to group assessment was fairer than allocating a group mark, making the point that summative assessment is only valid when students are individually graded for their contributions. However these arguments failed to acknowledge the importance of developing team working and softer skills.

Conversely, the awarding of a group grade could be preferable to individual grading due to the enhancement of learning opportunities through group presentation outweighing student criticism of group grades. Gibbs (2009) recommended the use of a mixed method approach to group assessment and went on to suggest a grading strategy incorporating limited emphasis on group work by assessment of the outcome of group work alongside individually marked assignments.

Biggs (2003) found that constructive alignment led to deep learning, development of critical thinking skills and improved performance. Group work assessment enhanced the learning of students who did less well using traditional assessment methods. Overwhelmingly, current literature suggests that group work assessment is advantageous in preparing students for practise, prepares students in developing life-long learning approaches and promotes responsibility for one's own learning required of a registered nurse.

\section{Methodology of assessments}

Most assessment in HEl's has a summative function which demonstrates the extent of a learner's success in meeting course requirements and contributes to their final mark. Formative assessment provides ongoing feedback in order to improve throughout a period of learning. In addition, Bloxham (2015),found the use of formative assessment can support students to reflect upon what they have learnt and enhance team working skills. 
Bloxham (2015) suggested that formative assessment should not be contaminated by summative purposes. As the reflective online log assessment within this module attracts a summative grade, students could be reluctant to admit they do not understand something or ask for help. Alternatively, reflective accounts encourage students to respond to formative assessment in a spirit of collaborative partnership. Indeed, the fact that the reflections count towards the summative assessment may enhance engagement and motivate the student to ask more questions and seek additional support.

Although formative assessment more closely reflects the HEl's principles, in order to certify student achievement, the validity of summative assessments are important. The assessment task therefore must demonstrate intrinsic validity by assessing that the learning outcomes have been achieved for the module, whilst at the same time ensure students build upon feedback during learning (Bloxham 2015). Therefore, the final grade must reflect the learning journey and the quality and content of the overall submissions, thus allowing for a student who struggles with the reflective element in the beginning to achieve a higher mark as their learning emerges.

\section{$\underline{\text { Reflection and assessment }}$}

The inclusion of reflection in assessment can enhance professional development. Reflection could be considered a strategy which integrates theory into practice, requiring students to analyse and evaluate their learning experiences therefore linking learning outcomes with the assessment strategy (Langley and Brown 2010).

Reflection can benefit students personally by helping students identify their own strengths and limitations. Langley and Brown (2010) found reflective logs supported students constructed meaning of learnt material and experience; clarified opinions, explored beliefs and feelings; developed change agents; and equipped students for real world practice.

However, reflection does have limitations. Preparation of, and the formative feedback involved in reflective logs, is time consuming (Langley and Brown 2010). In addition, being open in reflections requires students to trust the teacher. Students may be inhibited in their reflections and only include content which they believe would be acceptable, thus limiting the full benefits of the reflective process. The use of constructive alignment alongside reflective journals may limit the extent of learning. Therefore, there is a need for clear guidance, reassurance and confidencebuilding to be incorporated into instructions.

There is a paucity of guidance about assessment of reflection. The nursing literature offers insight into issues of reflection but no solutions. This compounds the difficulty of separating student knowledge and the ability to reflect upon it. Langley and Brown (2010) call for additional research to determine the impact of reflective journaling on teaching strategies of future educators. 


\section{LEARNING THEORY AND CONSTRUCTIVE ALIGNMENT THEORY}

HEIs require students to think critically and graduate with life skills which enhance their employability. In order to achieve both, there is a need for clear links between outcomes and approaches to teaching as to how to incorporate graduate attributes into the assessment process. Recent literature suggests placing emphasis upon a student-learning focussed approach can bridge the gap between student knowledge, understanding and graduate attributes. Achievement requires teachers to move from focusing on the content of the syllabus to critically reflecting on how students learn and adjusting teaching to meet the learning outcomes accordingly (Gibbs 2009).

Constructivist learning theory acknowledges the need to link new subject knowledge to existing concepts and experiences of the learner. Learning not only involves acquisition of new information, but involves changing students' views and comprehension of existing knowledge. Students' experiences and views need to be understood by the teacher in order to build upon them or challenge the way in which the student is thinking. If this change does not occur, learning may be disjointed. In order to achieve deeper learning, a teaching theory linking teaching, students and subject content through an overarching system is required. Teaching should be collaborative in nature to ensure learners change their understanding and involve discovery of student misunderstandings, interventions to change them and creation of a context of learning which encourages active engagement with the subject matter. The teacher focuses on the key issues that represent critical barriers to student learning, the content to be taught and student problems with learning direct the methods used. Theory three as described by Ramsden (1996) incorporates a deeper learning approach, continual improvement of skills and multiple teaching techniques to encourage learning.

Biggs (2003) argued that as well as developing a learning programme based upon constructivist teaching theory, that teachers needed to develop a constructively aligned curriculum where learning outcomes are aligned with the teaching environment and modes of assessment. The teacher must strive to understand how students construct meaning whilst carrying out learning activities and provide a supportive learning environment promoting achievement of learning outcomes (Biggs 2003). The process of constructive alignment involves 4 steps, defining learning outcomes; choosing teaching/learning activities most likely to lead to the achievement of learning outcomes; assessment of the learning outcomes and how they match; and arrival at a final grade (Biggs 2003).

\section{DISCUSSION}

Biggs (2003) argued that as well as developing a learning programme based upon constructivist learning theory, that teachers must develop a constructively aligned curriculum where learning outcomes are aligned with the teaching environment and mode of assessment. The outcomes of the project related to the module entitled 
"Mental Health Nursing 1", which was a 12 week module for 1st year undergraduate mental health student nurses. Details of the learning outcomes can be found at table 1. The teacher strived to understand how students constructed meaning whilst carrying out learning activities and endeavoured to provide a supportive learning environment which promoted achievement of module learning outcomes and selected activities considered most likely to lead to the achievement of module learning outcomes. (Biggs 2003).

The process of constructive alignment involved four steps. The first step was to define learning outcomes. The module learning outcomes had been developed prior to the teacher being appointed and could not be altered. The second step was selection of learning and teaching activities. The teacher took a blended learning approach which incorporated face to face lectures, small group tutorials, group activities, online activities, individual reading and online reflective logs, which maximised the opportunity for students to achieve the learning outcomes. The third step was assessment of learning outcomes and how they matched, and the fourth step was the arrival at a final grade. Steps three and four were of particular relevance to the project.

The existing module assessments stated 'presentation', and 'reflective log' and were provided on the module descriptor and could not be altered, however this project took a novel approach to assessment and changed the way in which the presentation was assessed and graded to incorporate constructive alignment theory. The change to assessment and grading was discussed between the teacher, teaching colleagues and first year mental health student nurses and changes implemented. One assessment of the module comprised of a group presentation linked to the module learning outcomes. The assessment question (table 3) was aligned to the module learning outcomes and considered relevant to the level of subject knowledge learners required at this stage of their programme by the module teacher, internal moderator and head of division. In previous cohorts, despite the assessment being a group presentation, the assessment of the presentation was only made of each individual. This appeared to constitute a surface level to assessment (Gibbs 2009), which although was useful in assessing each individual's presentation skills and subject knowledge of the part they presented, did not assess the overall group performance concerning construction of the presentation, how the individual worked or contributed as a group member, or considered the benefits to development of the softer skills of team working.

The group work assessment question offered students a choice of which mental health condition they presented. Through discussion with student groups during the module, provision of choice was reported to the teacher as having increased students' motivation to learn; built up communication and negotiation skills; prompted learners to begin to think critically; improved analytical skills; promoted team working; stimulated the need to plan the project and meet deadlines; helped students manage conflict; increased the amount of reading carried out; and helped develop information technology skills (Gibbs 2009). In taking a constructively aligned 
approach, the teacher's role developed into one of facilitation; prompted independent learning; and provision of struture.

Gibbs (2009) emphasised the need for learners to be clear about the purpose of group work and the assessment process. As well as being provided in the module handbook (appendix 3), the need for both individual and group assessments were discussed with students on several occasions. Overwhelmingly, students agreed that a comprehensive and fair way to assess their learning would incorporate three elements: a group presentation with an individual assessment grade, a group presentation with a group assessment grade, and an individual reflective online log. The online reflective logs were stored in a private online space where each individual learner was required to write (post) a reflective account regarding their learning. Only teaching staff could access and comment upon the posts. The posts contained reflections from learners reflecting upon the benefits of being taught through a constructively aligned module such as high confidence levels when out in their first practice placement; development of team working skills; and deeper learning of the mental health condition presented through the process of searching for relevant evidence.

The practical changes required in order to develop a constructively aligned assessment were modelled on the work of Sharp (2006) (table 2). Therefore, the way in which the presentation was assessed was reviewed to incorporate the elements of constructive alignment underpinned with constructivist theory. The individual performance during the group presentation was worth $25 \%$ of the total grade and was summative in nature. The second summative assessed element concerned the group performance and was worth $25 \%$ of the total grade. The online reflective log was commented upon by the module teacher thus provided formative feedback throughout the duration of the module. A final summative grade was awarded on completion of the logs worth $50 \%$ of the total grade. The sum of the three grades were calculated into an overall grade which met the quantitative needs of the $\mathrm{HEl}$.

Learners were asked for feedback regarding their satisfaction with the three summatively assessed elements. All students agreed that assessment of individual performance, group performance and individual reflective logs had led to a holistic assessment of their learning, however there were differences of opinion which emerged regarding the weighting of the three elements, with some students having felt that a higher percentage of the overall grade should have been attributed to the individual performance rather than the reflective logs. The rationale for weighting of multiple assessed elements is an area which requires further research.

From the module teacher's perspective, despite the benefits of a constructively aligned module as identified previously, the common criticisms of constructive alignment in the literature did emerge during the module (Biggs 1996: Biggs 2003: Gibbs 2009). The criticisms included the time taken to restructure, organise and prepare teaching and ensuring that the module met with the institutional requirements of the quantitative reporting and grading of the HEI. However given the 
positive feedback from learners and the depth of individual reflections regarding learning, the module teacher concurred with Biggs (2003) who argued that despite these limitations, by balancing teaching goals, student requirements, the learning outcomes, the teaching methods selected, the assessment design, the learning milieu and the philosophy of the $\mathrm{HEI}$, that effective teaching and deeper learning had been achieved. The use of constructive alignment and constructivist theory led to the redevelopment of a module which had effectively linked deeper learning, blended teaching and outcome-based assessment.

\section{CONCLUSION}

Constructive alignment theory is the alignment of learning outcomes, selection of teaching and learning activities most likely to lead to the achievement of learning outcomes, assessment of the learning outcomes and how they match, and arriving at a final grade. By aligning these elements, deep learning can occur, but the use of constructivist learning theory was required in order to establish the elements being aligned (Biggs and Tang 2007).

In terms of pedagogical assessment, the strengths and limitations of group work assessment have been discussed in the literature (Biggs 1996: Biggs 2003; Biggs and Tang 2007; Bloxham 2015; Gibbs 2009; Sharp 2006; Smith and Rogers 2014). Strengths included the alignment of teaching goals, student requirements, curriculum, teaching methods, assessment design, the learning milieu and the philosophy of the institution. Utilising a constructive alignment theory can lead to achievement of effective teaching and deeper learning. However, the limitations of constructive alignment theory include the time taken to restructure, organise and prepare teaching; and ensuring the curriculum met institutional requirements of quantitative reporting and grading.

Following discussion with teaching colleagues and learners, the assessment of the group presentation in one undergraduate module were changed from awarding one grade for individual performance within the group presentation to incorporate two elements; individual performance during the group presentation and overall group performance during presentation.

Both the strengths and limitations of implementing a constructively aligned module were reflected in the challenges and opportunities encountered by the module teacher when changes were made to how the group presentation was assessed and graded. Feedback from learners indicated satisfaction with the changes made, in that a comprehensive assessment of attainment of learning outcomes had occurred, however learner's views differed on the weighting of the three assessed elements. Therefore, more research is required into how multiple assessed elements are weighted to produce an overall grade.

Regarding the assessment of reflective logs, learners reflected that they felt knowledgeable regarding the mental health condition they had presented upon, and 
this learning of subject knowledge was useful within their first practice placement, however the effectiveness of a constructively aligned module in terms of readiness of learners for their first practice placement, has not been addressed in this project and requires future research. A gap in the research has also been identified in how to assess and grade reflective online accounts.

\section{REFERENCES}

Biggs, J.B. (1996) Assessing learning quality: Reconciling institutional, staff and educational demands, Assessment and Evaluation in Higher Education, Vol.21: p.5-15.

Biggs, J. (2003) Aligning teaching and assessment to curriculum objectives, LTSN Generic Centre, Imaginative Curriculum Project.

Biggs J., and Tang, C. (2007) Teaching for quality learning at university, Society for research in higher education, Buckingham, Open University Press.

Bloxham, S. (2015) Assessing assessment. New developments in assessment design, feedback practices and marking in higher education, IN: H Fry, S. Ketteridge and S. Marshall, A handbook for teaching and learning in higher education. Enhancing academic practice ( $4^{\text {th }}$ ed.), Oxon, Routledge.

Gibbs, G. (2009) The assessment of group work: Issues from the literature. Available from http://neillthew.typepad.com/files/groupwork-gibbs-dec-09.pdf Last accessed 3rd March 2016.

Langley, M.E., and Brown, S.T. (2010) Perceptions of the use of reflective learning journals in online graduate nursing education, Nursing Education Perspectives, Vol. 31(1):p. 12-17.

Ramsden, P. (2006) Learning to teach in higher education, London, Routledge.

Sharp, S. (2006) Deriving individual student marks from tutor's assessment of group work. Assessment and evaluation in higher education. Vol. 31(3):p. 329-343.

Smith, M., and Rogers, J. (2014) Understanding nursing students' perspectives on the grading of group work assessments. Nurse Education in Practice. Vol.14:p.112-116. 